\title{
Identifying the Maximum Concentration of Results in Bilateral Sports Competitions
}

\author{
Antonio Avila-Cano ${ }^{1}\left(\mathbb{D}\right.$, Amparo Ruiz-Sepulveda ${ }^{2}(\mathbb{D})$ and Francisco Triguero-Ruiz ${ }^{2, *(D)}$ \\ 1 Department of Economics and Economic History, University of Malaga, 29013 Málaga, Spain; aavila@uma.es \\ 2 Department of Languages and Computer Science, University of Malaga, 29071 Málaga, Spain; aruizs@uma.es \\ * Correspondence: triguero@uma.es; Tel.: +34-620-14-57-52
}

Citation: Avila-Cano, A.;

Ruiz-Sepulveda, A.; Triguero-Ruiz, F.

Identifying the Maximum

Concentration of Results in Bilateral Sports Competitions. Mathematics 2021, 9, 1293. https://doi.org/ $10.3390 /$ math9111293

\section{Academic Editors: Nikolaos}

Sariannidis, Eleni Zafeiriou and Sofia Anastasiadou

Received: 27 April 2021

Accepted: 2 June 2021

Published: 4 June 2021

Publisher's Note: MDPI stays neutral with regard to jurisdictional claims in published maps and institutional affiliations.

Copyright: (c) 2021 by the authors. Licensee MDPI, Basel, Switzerland. This article is an open access article distributed under the terms and conditions of the Creative Commons Attribution (CC BY) license (https:/ / creativecommons.org/licenses/by/ $4.0 /)$.

\begin{abstract}
There are situations in which a monopoly solution cannot be reached. In these cases, which situation represents the maximum concentration (minimum competitive balance)? It is a relevant question, given that in sports economics, measuring the competitive balance of a league is done through normalized indices. These indices require that the maximum level of concentration be known. Until now, the distribution of results that generates the maximum level of concentration has been identified in the literature as Complete cascade distribution. However, if the scoring system used does not fulfil the stability condition, which implies that the total number of points of a championship is constant, it can be demonstrated that the Complete cascade distribution does not generate the maximum level of concentration. This is the case, for example, with major European football leagues. In this article, we constructed a perfectly unbalanced distribution, which we called a Truncated cascade distribution. This distribution generates the maximum concentration level. Therefore, if we do not use Truncated cascade distribution, there is an overestimation of the concentration measured with normalized indices. Then, the calculated competitive balance will be wrong, that is, underestimated. We provided a spreadsheet for identifying this distribution.
\end{abstract}

Keywords: operational research in sport; exact solution procedure; sports economics; maximum concentration; bilateral sports competitions; competitive balance

\section{Introduction}

The concept of concentration is used in industrial economics. This variable measures the level of market concentration as a function of firms' size distribution, that is, it measures the degree of control that larger firms have over the market. If all the firms are of the same size, this variable reaches its minimum value, whereas if only a few companies make up a major part of the market, it reaches its highest value. A monopoly would represent the extreme case.

While it is true that concentration has been comprehensively developed in economics, with its principal application being market structure in the field of industrial economics, it can be conceptually applied or lend itself to other areas of analysis. In fact, one of the pioneering authors in this sense, Hirschman [1], proposed an index for studying foreign trade that bears his name. Health economics [2,3], political science [4,5], sports economics [6,7], space economics [8], linguistics [9,10], and finance [11,12] are also noteworthy. These fields have highlighted the relationship between concentration and other variables, such as inequality, polarization, diversity, dispersion or fractionalization [13].

However, there are certain areas in which the representative configuration of the maximum concentration is not that of a monopoly. In effect, in the case of the markets, the vector of the size of the firms is the result of a competitive process in which each and every firm interacts with its competitors in multiple ways. However, there are competitive processes in which this is not true: sports competitions are competitions of a bilateral nature, there are no multiple encounters, and no one can accumulate the total result [14]. 
The most commonly used concept to analyze this phenomenon is competitive balance. Competitive balance is a basic and current concept in sports economics [15]. As in industrial economics, this concept indicates the degree of control exercised by the major teams, measured in terms of points obtained at the end of the championship or other metrics, such as wins. Therefore, there is an inverse relationship between competitive balance and concentration. From an ex-post point of view, this is related to the number of points (or wins) reached by the teams and, therefore, the competitiveness demonstrated over the season. This extent of competitive balance is a central feature in the design of professional team sports leagues [16].

The extent to which playing strengths vary between teams has important implications for the uncertainty surrounding the outcomes of individual matches and overall competitions. According to the uncertainty of outcome hypothesis [17], the less predictable the outcome of a sports match, the greater the consumer interest, which is reflected in higher match attendance and higher television audiences. Therefore, if the uncertainty contributes to consumer demand for sports, we can expect that greater competitive balance should increase team revenue. Nevertheless, it may be that there is no reason for fans to even care about outcome uncertainty, so competitive balance should have little impact on fan demand [18]. Moreover, it is possible for fan interest to increase, even as win uncertainty decreases [19].

Consequently, the competitive balance and attractiveness of leagues is a key consideration for league organizers and a focus for the analysis of sport competitions in several disciplines, such as economics, operations research and statistics [20-27]. Measurement is therefore important, either to track movements in the within-season competitive equilibrium over successive seasons and assess the effects of regulatory and institutional changes, or to examine the effects of changes in the competitive equilibrium on consumer demand for sports competitions [28].

How do we measure competitive balance? There are approaches based on probabilistic measures [29], although these measures do not contemplate the possibility of ties, and there are measures of uncertainty of outcome that are also used [30-32] to measure competitive balance, using money lines. However, to measure the competitive balance of a tournament, it is common to use indices.

These indices summarize the distribution of scoring at the end of the tournament [6,33-35] and they are linked to inequality and concentration indices: Gini [36-39], concentration ratio [40], entropy index [41-43] or Herfindahl-Hirschman index [7,44,45].

It is possible to find many examples of real situations in which, given the characteristics of a competition, a monopoly does not represent the configuration that generates the minimum competitive balance as measured by concentration indices, such as the Herfindahl-Hirschman index applied to the point shares achieved by the teams that contested the championship. This is the case in bilateral sports competitions, such as the leagues of the most popular sports (football, rugby, American football, baseball, basketball, hockey, and handball, to name just a few) in which it is not possible for a single team to accumulate the total number of points, as it does not participate in all the encounters. Kharrat [46] pointed out the need to take into account differences in the competitiveness of leagues to evaluate the performance of football players. This assessment is of interest to team managers, coaches and fans.

In the case of industrial concentration measurements, various indices have been proposed and traditionally used [47-49]. The Herfindahl-Hirschman index (HHI), defined as the sum of the squares of the individual market share of firms, has reached the greatest acceptance and dominance in the literature. Different versions of the HHI have been used in studies on a wide variety of sports. A non-exhaustive list includes American football $[33,50,51]$, association football [44,45,52-55], Australian rules football [56,57], baseball [7,58], basketball [59-61], ice hockey [62], rugby league [57,63], and table tennis [64].

Most of these indices incorporate specific characteristics of sport competitions. In a bilateral sports competition, the range of variation in competitive balance measurements is 
subject to specific constraints. Indeed, there are aspects that influence competitive balance measurements and restrict the theoretical range of traditional concentration indices [14]. Among these sport-specific issues, there are three relevant ones that influence the index range: (i) the impossibility of a team reaching a monopoly position, (ii) the scoring system adopted, and (iii) the number of teams in the tournament. When the value of competitive balance reaches its maximum, that is, when all teams have the same score, the number of teams competing becomes relevant to define the theoretical range of the index to compare different leagues, which can have different numbers of teams $[7,33,62,64,65]$. Similarly, as the monopoly position cannot be reached due to the bilateralism of the encounters (only two teams can meet in any one competitive encounter, as mentioned at the beginning of the Introduction), the results configuration that generates the minimum competitive balance must be considered, and this is determined by the scoring system used.

For this reason, various proposed indices take these issues into account to a greater or lesser degree, and most of the measures currently used are relativized with respect to the maximum or minimum values that they can reach. Since these indices are normalized, they have a theoretical unit interval. More specifically, we can find two competitive balance indices that have index concentration standardization included in their definition:

- Standardized Herfindahl-Hirschman index [58]:

$$
\mathrm{HHI}_{\mathrm{N}}=\frac{\mathrm{HHI}-\mathrm{HHI}_{\min }}{\mathrm{HHI}_{\max }-\mathrm{HHI}_{\min }}
$$

- Distance to competitive balance [66]:

$$
\mathrm{DCB}=\sqrt{\mathrm{HHI}_{\mathrm{N}}}
$$

It is shown that $H H I_{N}=\frac{\sigma^{2}-\sigma_{\min }^{2}}{\sigma_{\max }^{2}-\sigma_{\min }^{2}}$, where $\sigma^{2}$ represents the variance of the shares of teams [39]. On the other hand, DCB index enables the result to be interpreted as a mathematical distance that fulfils the cardinality property and, therefore, maintains its ratios and permits the differences between index values to be significant.

Both indices require knowing the maximum and minimum values that can be reached in a sports championship, the sum of the square of the score share of all participating teams.

Given the number of teams in a championship, the maximum competitive equilibrium is reached when there is an even distribution of results (that is, when none of them stands out from the rest). This result is provided by the perfectly balanced distribution [43]. In this distribution, the share of points is equal for all of them, so the teams get the same number of points. In these cases, the value of the HHI is equal to the inverse of the number of teams [7]. Therefore, the maximum balance depends on the number of teams in the competition.

The perfectly balanced distribution of scores indicates that all teams have an equal likelihood of winning a match and, subsequently, the championship. This result can be obtained when either all matches end in a tie, or, if there is no possibility of a tie and with a double round-robin system, each team wins and loses matches against the same opponent. In the field of sports economics, these issues are well known as bilateral confrontations.

Our interest is focused on the calculation of the perfectly unbalanced distribution of the scores, that is, the distribution that generates the $\mathrm{HHI}_{\max }$. Its configuration allows any competitive balance index that requires this value, such as $\mathrm{HHI}_{\mathrm{N}}$ or DCB index, to be calculated.

What is the minimum value, and what distribution of results generates it? The distribution generally used so far is not the perfectly unbalanced distribution if the scoring system does not fulfil a stability condition (the total number of points of the championship is constant). The current scoring system in European football does not fulfil this condition because $p_{w}=3$ points are awarded for a win, $p_{t}=1$ point is awarded for a tie, and $p_{l}=0$ points are awarded for a loss. Therefore, the standardized indices being used are not correct. 
Until now, the distribution of results that generates the maximum level of concentration has been identified in the literature as Complete cascade distribution. However, if the scoring system used does not fulfil the stability condition, which implies that the total number of points of a championship is constant, it can be demonstrated that Complete cascade distribution does not generate the maximum level of concentration [14,67]. This is the case, for example, with major European football leagues. Therefore, if the total number of points at the end of the season varies, the perfectly unbalanced distribution so far used in the literature is not correct. Note that in a championship, several matches are played. At the end of each match, each team is remunerated according to the result achieved. This award is a certain number of points for winning, losing and, if necessary, tying. At the end of the championship, after all teams have played against each other, each team has a certain number of points. The amount of points will be the sum of the points obtained after each match. Therefore, if the remuneration system distributes a fixed number of points (e.g., two for the winner, zero for the loser, and one for each team in the case of a tie), the total number of points of the championship is constant (stability condition). However, a system that allocates three points to the winner, zero to the loser and one point to each team in the case of a tie implies that the total number of points at the end of the championship is not known from the beginning, that is, it is not constant and it does not fulfil the stability condition.

In this article, we calculate the minimum value of competitive balance, obtained from the perfectly unbalanced distribution. This value can be calculated prior to the competition so as to avoid recalculating the results and, as proposed, when the scoring system does not fulfil the stability condition $[39,45]$. We introduce a methodology for obtaining the perfectly unbalanced distribution, which allows to solve the knowledge gap in these situations. We demonstrate that the concentration index has a unique maximum for each number of teams. We also obtain the value of the index for a generic scoring system and show that there is a critical value of $q$ with which we obtain the perfectly unbalanced distribution of points. The top $q$ teams win their matches in cascade, while for the teams in positions higher than $q$, all teams are tied. This critical value of $q$ is characterized by the solution of a fifth degree polynomial inequation. This value defines the Truncated cascade distribution of points that reaches the maximum index value of concentration, that is, the perfectly unbalanced distribution. This distribution generates the maximum concentration level and, if we do not use it, there is an overestimation of the concentration measured with normalized indices. Then, the calculated competitive balance will be wrong, that is, underestimated.

In particular, we obtain the perfectly unbalanced distribution for current European soccer with a scoring system of $\{3,1,0\}$, and characterize this distribution. In the Supplementary Materials, we propose a tool to obtain the most imbalanced distribution for any other scoring system of the same type $\left\{p_{w}, p_{t}, 0\right\}$.

In the Materials and Methods section, we define the formal frame of reference for bilateral sports competitions, analyzing their characteristics. In the Results section, we characterize the Truncated cascade distribution and show that this distribution reaches the maximum concentration level of a championship. The fourth section presents the Discussion and Conclusions in which we highlight the contribution of knowing the distribution of the maximum concentration in advance, for example, for normalization and, if necessary, for comparison. Three appendices provide proof of the results formulated in the Results section. Moreover, in the Supplementary Materials, we provide a Microsoft Excel spreadsheet that presents the Truncated cascade distribution for different scoring systems.

\section{Materials and Methods}

Perfectly unbalanced distribution is identified in the literature as the result of a competition, where, in the final ranking, the first team has beaten the rest; the second, all others except the first; and so on, until the last, which has lost all its games [68]. Due to its graphic representation, we called this the Complete cascade distribution. It is true to say that if the total number of points of a championship is established from the beginning, 
this distribution will generate the $\mathrm{HHI}_{\max }$. However, this stability condition is not always fulfilled; in the scoring system currently used by the Union of European Football Associations (UEFA), it is not met, and therefore, the Complete cascade is not the distribution that generates the $\mathrm{HHI}_{\max }$. In the following paragraphs, we present the basic model that we follow in our analysis and characterize the Complete cascade distribution as the perfectly unbalanced distribution when this stability condition is fulfilled.

\subsection{The Model and the Perfectly Unbalanced Distribution of Scores}

We consider a league with $N \in \mathbb{N}$ and $N>1$ teams. The tournament can be played in a single or double round-robin system. The points assigned to each team in a match correspond to a pattern of the type $P=\left\{p_{w}, p_{t}, p_{l}\right\}$ ( $p_{w}$ points are awarded for a win, $p_{t}$ points are awarded for a tie, and $p_{l}$ points are awarded for a loss), where $p_{w}, p_{t}, p_{l} \in \mathbb{N}$, $p_{w}>p_{t}>p_{l}$ and $p_{w} \geq 2 p_{t}>p_{l}=0$ is assumed. Let $p_{i}, i \in\{1, \ldots, N\}$ be the number of points obtained at the end of the championship by the $i$ team; the subscript $i$ indicates the position of each team in the final ranking. The vector $\boldsymbol{p}=\left(p_{1}, p_{2}, \ldots, p_{N}\right)$ represents the final score of the championship. A new vector of shares $s=\left(s_{1}, s_{2}, \ldots, s_{N}\right)$ is defined, where $s_{i}=\frac{p_{i}}{\sum_{i=1}^{N} p_{i}}$. We define a competitive balance index as a function defined on the space of vectors of shares, which assigns to each vector of shares a value of the unit interval.

The number of matches played in a championship with $N$ teams is $N(N-1) / 2$, while each team plays $(N-1)$ matches in a single round-robin system. In the case of a k-round system, the total number of matches played in a season is $k N(N-1) / 2$, while each team plays $k(N-1)$ matches. This proportionality undermines the importance of the number of rounds in the aggregate analytical terms of a season.

The so-called perfectly unbalanced distribution was characterized by Fort and Quirk [69], Gayant and Le Pape [39,70], Horowitz [41], Owen et al. [58], and Utt and Fort [38], among others. In this distribution, "each team has defeated all those below them and have lost to all the teams above them. Once the tournament is over and the positions have been ordered, the results of distribution can be visualised as being 'in cascade' in which each team has fewer points than the team in the preceding position" [38].

Figure 1 shows this for $N=20$ with a $\{2,1,0\}$ pattern in a single round-robin system.

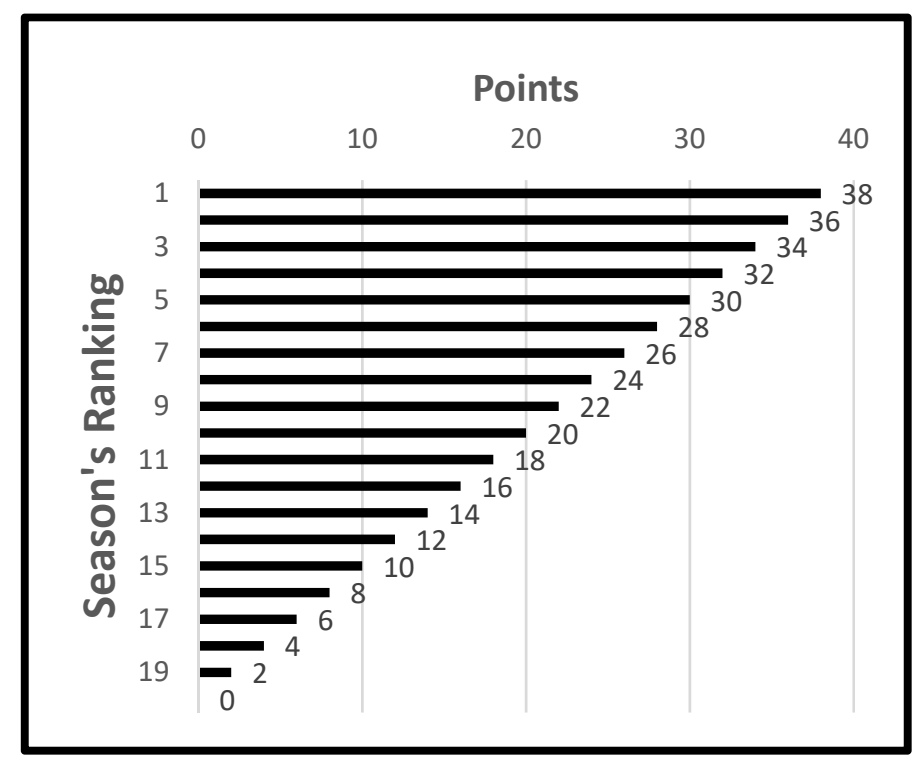

Figure 1. Complete cascade distribution $(N=20)$.

The Complete cascade distribution, identified in the literature as the most concentrated for a $\{2,1.0\}$ point pattern, visually corresponds to an inverted staircase (Figure 1 ). This most unbalanced distribution is also achieved with other patterns as is the case when no ties are allowed (as in baseball or basketball). The reason is that in the case of the pattern 
$\{2,1,0\}$ as in the case $\{1,0,0\}$ or $\{k, 0,0\}$, in each match the same number of points is distributed as opposed to a pattern of the type $\{3,1,0\}$ in which the number of points distributed depends on the outcome. The European soccer leagues use a point pattern $\{3,1,0\}$. The points distribution becomes unstable depending on the number of ties: with a point pattern $\{2,1,0\}$, at the beginning of each game, there are two points to be distributed among the teams and those two points are those that are assigned (both to the winner, or one to each team if they tie). However, with a system $\{3,1,0\}$, in the event of a tie, two points are awarded; if it is a win, three points are awarded to the winner. With a $\{2,1,0\}$ system, both teams are always awarded two points together at the end of the match; with a $\{3,1,0\}$ system, they can be awarded 3 if someone wins, or 2 if they tie.

The Complete cascade distribution is rarely formalized [39]. We will do so below.

First, in a single-round competition, the points obtained by the team in position $i$ have won $N-i$ matches:

$$
p_{i}=p_{w} \cdot(N-i) \text { for } i=1 \ldots N
$$

In the case of competitions with $k$ rounds, the value of $p_{i}$ shall be multiplied by $k$, that is, 2 in the case of round-robin competitions.

Second, the higher concentration, lower competitive balance is obtained in such a distribution where the team in position $i$ wins all its matches against teams in position $j>\mathrm{i}$ and loses its matches with teams in position $1<m<i$. The scoring system $\{2,1,0\}$ at the end of the season distributes a fixed number of points, that is, it does not depend on the results of each match.

If $\sum_{i=1}^{N} p_{i}$ is constant, the marginal value of $\mathrm{HHI}$ is as follows:

$$
\frac{\partial \sum_{i=1}^{N} s_{i}^{2}}{\partial s_{i}}=\frac{2}{\sum_{i=1}^{N} p_{i}} \cdot p_{i}
$$

Thus, as $\sum_{i=1}^{N} p_{i}$ is constant, the marginal value increases with the value of points obtained by the team. The maximum number of points that any team can score is limited by the maximum number of matches that it can win. The first team wins its $N-1$ matches, but from the second onwards, team $i$ can only defeat teams $j>i$ since it has lost to the first $i-1$ teams. This feature could be called the principle of saturation.

Ultimately, the contribution to the value of the concentration index for each point is increased with the points won by a team but it is limited (saturated) by the number of matches that it can win.

This result applies to scoring patterns of the type $\left\{p_{w}=2 \cdot p_{t}, p_{t}, p_{l}=0\right\}$.

Thirdly, the distribution of the results are $\mathbf{p}=\left(p_{w}(N-1), p_{w}(N-2), p_{w}(N-3), \ldots, p_{w}, 0\right)$. Given the total points $\sum_{i=1}^{N} p_{i}=\sum_{i=1}^{N} p_{w}(N-i)=p_{w} N(N-1) / 2$, the vector of shares are as follows:

$$
\mathbf{s}^{\mathrm{CCD}}=\left(\frac{1}{N}, \frac{N-2}{N(N-1)}, \frac{N-3}{N(N-1)}, \ldots, \frac{1}{N(N-1)}, 0\right)
$$

The share of the first team in this distribution is that of the N-teams in the perfectly balanced distribution [43].

\subsection{Complete Cascade Distribution and Stability Condition}

Let us imagine a league with four teams, each playing double round-robin with a scoring system $\{3,1,0\}$. This is the case for each group in the final classifying rounds of the UEFA Champions League (UCL). The Complete cascade distribution implies the vector of results $\mathbf{s}^{C C D}=(18,12,6,0)$ and generates $\sum_{i=1}^{N} s_{i}^{2}=0.389$. Would this be the maximum value that the concentration could reach? If so, then $H H I_{N}=1 \mathrm{y} \mathrm{DCB}=1$.

However, in this competition, there are, at least, three possible results, which contradict the above: (a) two teams win all their matches, except the one played against each other, which is a tie, and the remaining two teams tie with each other; (b) one team wins all its matches, as does the next team, except those that played against the first, and the other 
two teams tie with each other (but lose against the first two); and (c) one team wins all its matches, and the other three tie with each other.

The distribution of results is the following $\mathbf{p}^{(a)}=(14,14,2,2), \mathbf{p}^{(b)}=(18,12,2,2)$, and $\mathbf{p}^{(c)}=(18,4,4,4)$. The corresponding values of the sum of the square of the score share is the following: $\mathrm{HHI}^{(\mathrm{a})}=0.391, \mathrm{HHI}^{(\mathrm{b})}=0.412 \mathrm{y} \mathrm{HHI}^{(\mathrm{c})}=0.413$. All these are greater than $\operatorname{HHI}\left(\mathbf{s}^{C C D}\right)=0.389$. Therefore, if we assume that $\mathbf{s}^{C C D}$ represents the distribution that generates the maximum concentration, the values that we calculate for $\mathrm{HHI}_{N}$ and the DCB index are greater than the whole, which is impossible, given the fact they are standardized.

This example clearly shows that the Complete cascade does not necessarily have to be the distribution that generates the maximum value of $\sum_{i=1}^{N} s_{i}^{2}$ as it does not represent the perfectly unbalanced distribution in all cases. What is the reason for this?

The scoring system establishes the rewards or incentives for winning. It is part of the mechanism that generates results in a competition. The possibility of ties occurring with a system of the type $\{3,1,0\}$, as mentioned above, demonstrates that the number of total points at the end of the championship can vary depending on the results of each match, and the distribution of points will be unstable.

Below is a condition that guarantees the stability of the number of points allocated in a tournament.

Stability Condition. If $p_{w}=2 p_{t}$, the number of points obtained in a tournament, $\sum_{i=1}^{N} p_{i}$, with $N$ teams does not depend on the results obtained by each match $[39,43]$.

This stability condition can be generalized with Lemma 1, including the points obtained by the losing teams, $p_{l}$.

Lemma 1. If $p_{t}=\frac{p_{w}+p_{l}}{2}$ or $w=N(N-1) / 2$, then the stability condition is fulfilled.

Proof. Let $w$ be the number of wins and $t$ the number of ties in a tournament. Then $w+t=N(N-1) / 2$. Let $x=\frac{w}{N(N-1) / 2}$ be the proportion of matches with a winner, $1-x=\frac{t}{N(N-1) / 2}$ be the proportion of matches without a winner, that is, tied matches. The total points at the end of a championship is as follows:

$$
\begin{aligned}
\sum_{i=1}^{N} p_{i}= & p_{w} w+2 p_{t} t+p_{l} w \\
& =\left(p_{w}+p_{l}\right) \cdot x \cdot N \cdot \frac{(N-1)}{2}+p_{t} \cdot(1-x) \cdot N \cdot(N-1) \\
& =N \cdot(N-1) \cdot\left[\left(p_{w}+p_{l}\right) \cdot \frac{x}{2}+p_{t} \cdot(1-x)\right] \\
& =N \cdot(N-1) \cdot\left[\left(\frac{\left(p_{w}+p_{l}\right)}{2}-p_{t}\right) \cdot x+p_{t}\right]
\end{aligned}
$$

Then, if $p_{t}=\frac{p_{w}+p_{l}}{2}$ or $w=N(N-1) / 2$, the total championship points $\sum_{i=1}^{N} p_{i}$ only depends on $N$ and scoring pattern.

When the stability condition is not fulfilled, instability is generated, which is identified as one of the main problems in measuring competitive balance [39].

In this case, how can we calculate a perfectly unbalanced distribution? Additionally, how can we apply the principle of saturation? Given that the marginal contribution to the value of the HHI concentration index increases with the number of points obtained by the team, the winning matches should be accumulated among the top teams in the ranking, while the rest should be tied. Thus, the highest HHI value is obtained when the teams at the top of the ranking win all their matches with the teams below them in the final ranking.

Therefore, the real issue is that the Complete cascade distribution is not perfectly unbalanced in all cases. The Complete cascade distribution is the least balanced distribution when the stability condition is satisfied. However, with another pattern, the perfectly unbalanced distribution is different from the Complete cascade distribution. 


\section{Results}

In this section, we demonstrate that the HHI has a unique maximum for each $N$, called $\mathrm{HHI}_{\text {max }}$. We also obtain the value of $\mathrm{HHI}$ for a generic scoring system and show that there exists a critical value of $q$ with which we obtain the most concentrated distribution of points. The top $q$ teams win their games in cascade, while for teams in positions higher than $q$, all teams are tied. This critical value of $q$ is characterized by the solution of a fifth-degree polynomial equation.

\subsection{Distribution of Scores}

We define a type of asymmetric distribution of points, characterized by a $q$ value in which the top $q$ teams win their matches in cascade, while for teams in positions higher than $q$, all teams are tied. Therefore, in this type of point distribution, two groups of teams emerge: those that have won at least one match and those that have not won any match, tying with each other.

Remark 1. Note that, for each $q$, the number of points is constant. Therefore, the saturation principle can be applied to each value of $q$.

For every $0 \leq q<N$, with $q \in \mathbb{N}$, a generalized distribution is obtained, which we call the Truncated cascade in (q) distribution. For the value $q=0$, the teams tie all their matches, and we obtain a perfectly balanced distribution. For the value $q=N-1$, the teams win their matches in a cascade, that is, their point distribution coincides with the classical Complete cascade distribution.

Let us now consider a pattern $P=\left\{p_{w}, p_{t}, 0\right\}$; in this case, the points obtained by the teams are as follows:

$$
p_{i}=\left\{\begin{array}{l}
p_{w} \cdot(N-i) \text { for } i=1 \ldots q \\
p_{t} \cdot(N-q-1) \text { for } i=q+1 \ldots N
\end{array}\right.
$$

\subsection{The Corresponding Herfindahl-Hirschman Index}

In a competition with $N$ teams, Proposition 1 allows us to obtain the expression of $\mathrm{HHI}$ as a function of the $q$-value, for a Truncated cascade distribution in $(q)$.

Proposition 1. For every $0 \leq q \leq N-1$, with $q \in \mathbb{N}$, and $\{3,1,0\}$ scoring system, the value of HHI is the following:

$$
\operatorname{HHI}(q)=\frac{2 \cdot q^{3}+\left(-6 \cdot N+\frac{5}{2}\right) \cdot q^{2}+\left(6 \cdot N^{2}-5 \cdot N+\frac{1}{2}\right) \cdot q+N \cdot(N-1)^{2}}{\left(\frac{-q^{2}-(1-2 \cdot N) \cdot q+2 \cdot N \cdot(N-1)}{2}\right)^{2}}
$$

Proof. See Appendix A.

From there, for a competition with $\mathrm{N}$ teams with an established scoring pattern, we want to calculate the critical value $\left(q^{*}\right)$ that forces the HHI to reach its maximum value.

Theorem 1. Let $q \in \mathbb{N}$, with $0 \leq q<N$, then $H H I(q)$ has a unique maximum and minimum in $[1 / \mathrm{N}, 1]$.

Proof. See Appendix B. 


\subsection{The Cut-Off Value of $q$ for $\mathrm{HHI}_{\max }$}

In this section, we obtain, with Theorem 2, the cut-off value of $q$ that causes $\mathrm{HHI}=\sum_{i=1}^{N} s_{i}^{2}$ to reach its maximum value. For this purpose, we build a recurrent formulation of the transition of $\mathrm{HHI}$ between two consecutive values of $q$, with $0 \leq q<N$.

Theorem 2. Let $N$ be the number of teams in a tournament with a scoring pattern $\{3,1,0\}$; then, the maximum value of HHI is obtained by accumulating wins in the first $q^{*}$ teams, where $q^{*}$ satisfies the fifth-degree inequality:

$$
\begin{aligned}
0> & -\frac{1}{2} \cdot q^{5}+\left(\frac{5}{2} \cdot N-\frac{9}{4}\right) \cdot q^{4}+\left(-8 \cdot N^{2}+12 \cdot N-\frac{7}{2}\right) \cdot q^{3}+\left(11 \cdot N^{3}-27 \cdot N^{2}+18 \cdot N-\frac{9}{4}\right) \cdot q^{2} \\
& \left.+\left(8 \cdot N^{4}-6 \cdot N^{3}-9 \cdot N^{2}+\frac{15}{2} \cdot N-\frac{1}{2}\right) \cdot q-4 \cdot N^{5}+12 \cdot N^{4}-13 \cdot N^{3}+6 \cdot N^{2}-N\right]
\end{aligned}
$$

Proof. See Appendix C.

While with Theorem 1 we defined the existence of a single maximum value of $\mathrm{HHI}$, with Theorem 2, we constructively generated a polynomial inequation of the fifth degree from which we can obtain the cut-off value of $q$ to define the Truncated cascade distribution of points that reaches the maximum value of $\mathrm{HHI}$, that is, the perfectly unbalanced distribution, in a competition with $N$ teams and a scoring pattern $\{3,1,0\}$.

\subsection{Calculus and Results}

To perform the calculations that allow us to obtain the cut-off value of Theorem 2, we developed a Microsoft Excel spreadsheet, a tool that allows us to confirm the theoretical results already formulated and to obtain the cut-off value of $q$ for any $N$. This tool is provided in the Supplementary Materials.

Table 1 shows, for a score pattern $\{3,1,0\}$ and values of $N$ between 2 and 25, the maximum value reached by $\mathrm{HHI}$. As shown, the values of $\mathrm{HHI}_{\max }$ decreased with $N$, while the values of $q$ increased. However, the critical point of the cut-off value of $q$, where the $\mathrm{HHI}_{\max }$ is reached, can be observed in relation to higher and lower values. In the Supplementary Materials, we observed that the value of HHI, its numerator and denominator evolve. The values in bold in Table 1 show a perfectly unbalanced distribution.

Figure 2 shows graphically, for comparison with Figure 1, how the cascade of teams that won some games was interrupted at the 7 th rank with a scoring pattern $\{3,1,0\}$.

Table 2 compares the values of $q$ and $\mathrm{HHI}_{\max }$ for two scoring patterns: one that fulfils the stability condition, $\{2,1,0\}$, and one that does not, $\{3,1,0\}$. We observed that with the pattern of scores $\{2,1,0\}$, the cut-off value of $q$ was $N-1$, whereas with the pattern of scores $\{3,1,0\}$, the cut-off was truncated at a value less than $N-1$, which increased with $N$.

With the known maximum and minimum values of the $\mathrm{HHI}$ for a competition with $\mathrm{N}$ teams and scoring pattern $\{3,1,0\}$, we can standardize and, therefore, compare, using the DCB. This result provides an answer to the problem [39] of not being able to standardize the HHI for scoring patterns that do not fulfil the stability condition.

In the major European leagues and in the UEFA Champions League (UCL), the current scoring pattern is $\{3,1,0\}$. Specifically, in the qualifying round of UCL, there are groups of four teams. In this case, Table 2 shows that the cut-off value of $q$ was 1 , so the perfectly balanced distribution was associated with one team winning all its matches, and the rest of the teams tying with each other and losing to the first ranked team. So HHI $\max =0.413333$, and if the Complete cascade distribution is incorrectly used, $\mathrm{HHI}_{\max }=0.388888$. Similarly, in a league with 20 teams and a scoring system $\{3,1,0\}$, the cut-off value was 7 , and the $\mathrm{HHI}_{\max }$ was 0.075402 with the Truncated cascade distribution, while the $\mathrm{HHI}_{\max }$ value for the Complete cascade distribution was 0.068421 .

For each $\mathrm{N}$, the maximum of $\mathrm{HHI}$ with $\{3,1,0\}$ pattern was greater than the maximum of HHI with the $\{2,1,0\}$ pattern. Therefore, if we do not use the Truncated cascade distribution, there is an overestimation of the concentration measured with $\mathrm{HHI}_{\mathrm{N}}$. Then, the calculated competitive balance will be wrong, that is, underestimated. 


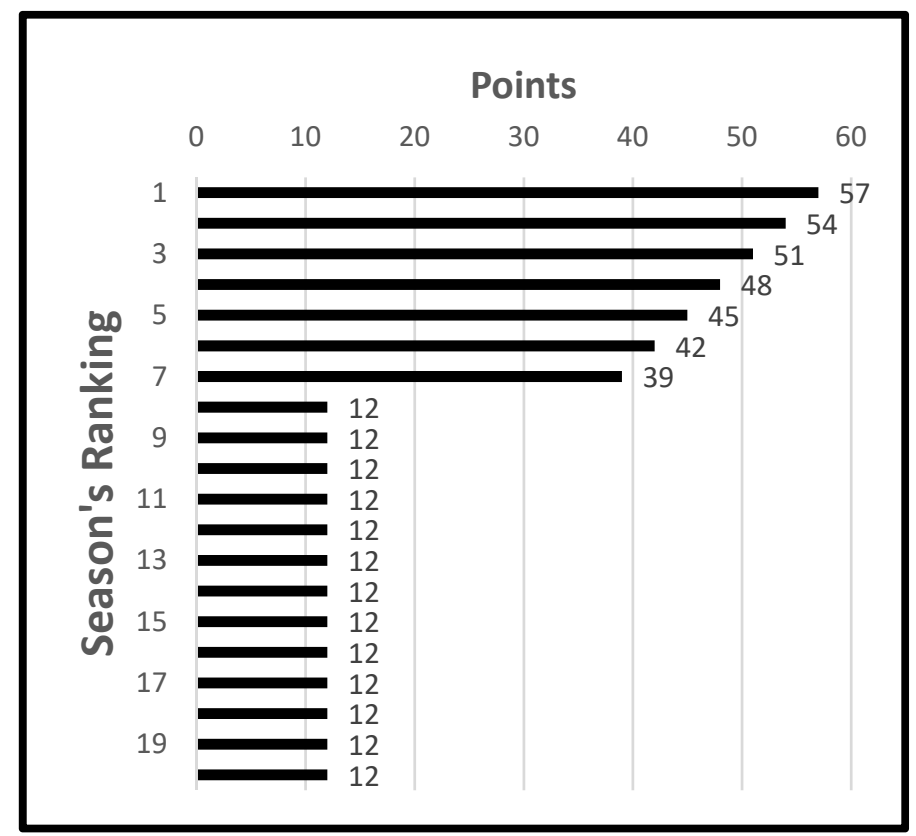

Figure 2. Truncated in $q^{*}=7$ cascade distribution $(N=20)$. Scoring pattern $\{3,1,0\}$.

Table 1. Value of the HHI as a function of the number of teams $(N)$ and of matches won in cascade $(q)$. Scoring pattern $\{3,1$, 0\}. (Maximum of HHI in bold.)

\begin{tabular}{|c|c|c|c|c|c|c|c|c|c|c|}
\hline \multirow{2}{*}{$\begin{array}{c}\text { No. of } \\
\text { Teams }(N)\end{array}$} & \multicolumn{10}{|c|}{ Matches Won in Cascade $(q)$} \\
\hline & 0 & 1 & 2 & 3 & 4 & 5 & 6 & 7 & 8 & 9 \\
\hline 2 & 0.50000 & 1.00000 & & & & & & & & \\
\hline 3 & 0.33333 & 0.59375 & 0.55556 & & & & & & & \\
\hline 4 & 0.25000 & 0.41333 & 0.41176 & 0.38889 & & & & & & \\
\hline 5 & 0.20000 & 0.31250 & 0.32510 & 0.31272 & 0.30000 & & & & & \\
\hline 6 & 0.16667 & 0.24898 & 0.26627 & 0.26190 & 0.25207 & 0.24444 & & & & \\
\hline 7 & 0.14286 & 0.20573 & 0.22392 & 0.22438 & 0.21833 & 0.21124 & 0.20635 & & & \\
\hline 8 & 0.12500 & 0.17460 & 0.19219 & 0.19540 & 0.19231 & 0.18701 & 0.18188 & 0.17857 & & \\
\hline 9 & 0.11111 & 0.15125 & 0.16766 & 0.17239 & 0.17139 & 0.16782 & 0.16354 & 0.15975 & 0.15741 & \\
\hline 10 & 0.10000 & 0.13315 & 0.14822 & 0.15374 & 0.15417 & 0.15200 & 0.14873 & 0.14532 & 0.14246 & 0.14074 \\
\hline 11 & 0.09091 & 0.11875 & 0.13250 & 0.13837 & 0.13976 & 0.13867 & 0.13632 & 0.13350 & 0.13077 & 0.12857 \\
\hline 12 & 0.08333 & 0.10705 & 0.11957 & 0.12551 & 0.12754 & 0.12726 & 0.12568 & 0.12347 & 0.12109 & 0.11890 \\
\hline 13 & 0.07692 & 0.09736 & 0.10877 & 0.11464 & 0.11708 & 0.11740 & 0.11645 & 0.11478 & 0.11280 & 0.11080 \\
\hline 14 & 0.07143 & 0.08923 & 0.09963 & 0.10534 & 0.10803 & 0.10880 & 0.10834 & 0.10714 & 0.10555 & 0.10382 \\
\hline 15 & 0.06667 & 0.08231 & 0.09181 & 0.09730 & 0.10015 & 0.10123 & 0.10117 & 0.10037 & 0.09913 & 0.09767 \\
\hline 16 & 0.06250 & 0.07636 & 0.08506 & 0.09031 & 0.09323 & 0.09454 & 0.09478 & 0.09431 & 0.09337 & 0.09218 \\
\hline 17 & 0.05882 & 0.07118 & 0.07918 & 0.08418 & 0.08711 & 0.08859 & 0.08907 & 0.08886 & 0.08819 & 0.08723 \\
\hline 18 & 0.05556 & 0.06664 & 0.07401 & 0.07876 & 0.08167 & 0.08327 & 0.08393 & 0.08394 & 0.08349 & 0.08274 \\
\hline 19 & 0.05263 & 0.06264 & 0.06944 & 0.07395 & 0.07681 & 0.07848 & 0.07929 & 0.07947 & 0.07921 & 0.07865 \\
\hline 20 & 0.05000 & 0.05908 & 0.06537 & 0.06964 & 0.07244 & 0.07416 & 0.07507 & 0.07540 & 0.07530 & 0.07490 \\
\hline 21 & 0.04762 & 0.05589 & 0.06173 & 0.06578 & 0.06851 & 0.07024 & 0.07124 & 0.07168 & 0.07172 & 0.07145 \\
\hline 22 & 0.04545 & 0.05302 & 0.05845 & 0.06229 & 0.06494 & 0.06668 & 0.06773 & 0.06827 & 0.06842 & 0.06827 \\
\hline 23 & 0.04348 & 0.05043 & 0.05549 & 0.05913 & 0.06169 & 0.06343 & 0.06452 & 0.06513 & 0.06537 & 0.06533 \\
\hline 24 & 0.04167 & 0.04807 & 0.05280 & 0.05626 & 0.05873 & 0.06044 & 0.06157 & 0.06224 & 0.06255 & 0.06260 \\
\hline 25 & 0.04000 & 0.04592 & 0.05035 & 0.05363 & 0.05602 & 0.05771 & 0.05885 & 0.05956 & 0.05994 & 0.06006 \\
\hline
\end{tabular}


Table 2. Least-balanced distributions for different numbers of teams and scoring patterns.

\begin{tabular}{ccccc}
\hline \multirow{2}{*}{$\begin{array}{c}\text { Number of } \\
\text { Teams (N) }\end{array}$} & \multicolumn{2}{c}{ Scoring Pattern $\mathbf{P}=\mathbf{2} \mathbf{2 , 1}, \mathbf{0}\}$} & \multicolumn{2}{c}{ Scoring Pattern $\mathbf{P}=\{\mathbf{3}, \mathbf{1}, \mathbf{0}\}$} \\
\cline { 2 - 5 } & $\begin{array}{c}\text { Cascade } \\
(\boldsymbol{q}=\mathbf{N}-\mathbf{1})\end{array}$ & $\begin{array}{c}\text { Maximum of } \\
\text { HHI }\end{array}$ & $\begin{array}{c}\text { Truncated } \\
\left.\text { Cascade } \boldsymbol{q}^{*}\right)\end{array}$ & $\begin{array}{c}\text { Maximum of } \\
\text { HHI }\end{array}$ \\
\hline 2 & 1 & 1.0000000 & 1 & 1.0000000 \\
3 & 2 & 0.5555556 & 1 & 0.5937500 \\
4 & 3 & 0.3888889 & 1 & 0.4133333 \\
5 & 4 & 0.3000000 & 2 & 0.3251029 \\
6 & 5 & 0.2444444 & 2 & 0.2662722 \\
7 & 6 & 0.2063492 & 3 & 0.2243767 \\
8 & 7 & 0.1785714 & 3 & 0.1953981 \\
9 & 8 & 0.1574074 & 3 & 0.1723899 \\
10 & 9 & 0.1407407 & 4 & 0.1541667 \\
11 & 10 & 0.1272727 & 4 & 0.1397569 \\
12 & 11 & 0.1161616 & 4 & 0.1275433 \\
13 & 12 & 0.1068376 & 5 & 0.1174003 \\
14 & 13 & 0.0989011 & 5 & 0.1087967 \\
15 & 14 & 0.0920635 & 5 & 0.1012346 \\
16 & 15 & 0.0861111 & 6 & 0.0947846 \\
17 & 16 & 0.0808824 & 6 & 0.0890706 \\
18 & 17 & 0.0762527 & 7 & 0.0839378 \\
19 & 18 & 0.0721248 & 7 & 0.0794709 \\
20 & 19 & 0.0684211 & 7 & 0.0754015 \\
\hline
\end{tabular}

In the literature, there are measurements of competitive balance, based on points scored at the end of the championship, which do not use standardized indices. We believe that such estimates should be reviewed. The use of standardized indices allows comparability between championships with different numbers of contenders.

If the championship scoring pattern fulfils the stability condition, the minimum competitive balance is well constructed from the Complete cascade distribution. However, if the scoring pattern does not fulfil the stability condition and normalized indices are used, the measurements should be redone using the Truncated cascade distribution. In the next section, we elaborate on this issue.

\section{Discussion and Conclusions}

So far, to compare the competitive balance between seasons, it was proposed to reconstruct the scores obtained with a $\{3,1,0\}$ scoring pattern to a $\{2,1,0\}$ pattern, based on the actual match results $[39,45]$ and using the Complete cascade distribution as a perfectly unbalanced distribution.

This recalculation generates cardinal and ordinal negative effects, and alters the values of the competitive balance index [55]. Therefore, for any model using competitive balance as a variable, the use of the reconstructed values for another scoring pattern may generate both quantitative and ranking errors. For example, if elasticity is estimated in a model, the results obtained using the reconstructed competitive balance are not correct. Note that calculating the competitive balance usually entails analyzing its evolution, together with its relationship with other characteristic variables of championships of sports: baseball [7], American football [33], football [71,72] are all good examples.

These problems arise from the inappropriate use of the Complete cascade distribution as a perfectly unbalanced distribution for scoring patterns that do not fulfil the stability condition.

In the case of the $\{3,1,0\}$ scoring pattern, the most common in soccer, it does not fulfil the stability condition and, in addition to the problem mentioned above, a new problem emerges, which Gayant and Le Pape [39] identified as one of the main problems in sport economics: the impossibility of standardization due to the lack of knowledge, at that time, of the least balanced, that is, most concentrated, distribution for that scoring pattern. 
In this paper, we identified and characterized the least balanced distribution for that scoring pattern, and therefore, we solved the problem generated by the fact of not knowing it a priori.

This identified generic distribution, which we call the Truncated cascade distribution, includes as a particular case the Complete cascade distribution, widely used in the literature for the $\{2,1,0\}$ scoring pattern.

Failure to use the most appropriate unbalanced distribution linked to the corresponding scoring pattern leads to an overestimation of the concentration and, as a consequence, to an underestimation of the competitive balance, generating both cardinal and ordinal problems. The reconstruction of the results is not neutral. Cardinal effects affect possible modeling in comparative studies, as the values of the indices change. The ordinal effects are even more severe, as they can affect the league's ranking for a season. One example is as follows. In the 2016/17 season, among the five major European football leagues, the Spanish Primera División was the most concentrated league $(\mathrm{DCB}=0.5367$ versus the Italian Serie A, with a DCB $=0.5366)$; if the data were reconstructed under a $\{2,1,0\}$ system, the league with the most concentrated results are the Italian Serie $A(D C B=0.5749$ versus the Spanish one, with a $\mathrm{DCB}=0.5697$ ). This same error can be checked for eleven of the twenty-one seasons between 1997/98 and 2017/18.

Another aspect to highlight is that to be able to compare competitions when some of their parameters change (number of teams or scoring system), it is necessary to normalize and, for this, it is necessary to know the maximum and minimum values of the index used, in this case, the HHI. This type of index also requires normalization that takes into account the specific characteristics of bilateral sports competitions.

Once the perfectly unbalanced distribution linked to the scoring pattern is known, we can construct a comparison with the necessary rigor and avoid problems derived from an unnecessary recalculation of the teams' scores in the respective seasons.

Another relevant issue is that the formulation developed in this article is generic as can be seen in Appendices A-C, so its particularization to other similar scoring systems is easily accessible. The spreadsheet contained in the Supplementary Materials allows for this without any difficulty.

An extension of these findings to other types of scoring patterns (inclusion of bonuses, double alternative scoring of ties, etc.) in bilateral sports competitions could be the focus of a future study.

Supplementary Materials: This following are available online at https:/ /www.mdpi.com/article/ $10.3390 /$ math9111293/s1. In the supplementary material, we provide a spreadsheet (MS-Excel) to identify the Truncated cascade distribution.

Author Contributions: Conceptualization, A.A.-C. and F.T.-R.; methodology, A.A.-C., A.R.-S. and F.T.-R.; software, A.R.-S. and F.T.-R.; validation, A.A.-C. and F.T.-R.; formal analysis, A.R.-S. and F.T.R.; investigation, A.A.-C. and F.T.-R.; resources, A.R.-S.; data curation, A.R.-S.; writing-original draft preparation, A.A.-C.; writing-review and editing, A.A.-C., A.R.-S. and F.T.-R.; visualization, A.A.-C. and A.R.-S.; supervision, A.A.-C. and F.T.-R.; project administration, A.R.-S.; funding acquisition, A.A.-C. All authors have read and agreed to the published version of the manuscript.

Funding: This research was funded by Secretaría de Estado de Investigación, Desarrollo e Innovación (Spain), grant number [ECO2017-86245-P] and the APC was partially funded by Universidad de Málaga.

Institutional Review Board Statement: Not applicable.

Informed Consent Statement: Not applicable.

Data Availability Statement: Not applicable.

Acknowledgments: We have benefited from comments of Rosario Gómez García and José Manuel Ordoñez from University of Malaga (Spain). The authors would like to thank two anonymous referees for their constructive comments and suggestions which have considerably improved this manuscript.

Conflicts of Interest: The authors declare no conflict of interest. 


\section{Appendix A}

Proof of Proposition 1. We can obtain HHI $=\sum_{i=1}^{n} s_{i}^{2}=\frac{\sum_{1}^{n} p_{i}^{2}}{\left(\sum_{1}^{n} p_{i}\right)^{2}}$ from the following expressions. The sum of points, whose square appears in the denominator, would be as follows:

$$
\begin{aligned}
\sum_{i=1}^{N} p_{i}= & \sum_{i=1}^{q} p_{w} \cdot(N-i)+\sum_{i=q+1}^{N} p_{t} \cdot(N-q-1)=p_{w} \cdot N \sum_{i=1}^{q} 1-\sum_{i=1}^{q} p_{w} \cdot i+p_{t} \\
& \cdot(N-q-1) \cdot \sum_{i=q+1}^{N} 1=\frac{p_{w} \cdot q \cdot(2 \cdot N-q-1)}{2}+p_{t} \cdot(N-q-1) \cdot(N-q) \\
& =\frac{\left(2 \cdot P_{t}-P_{w}\right) \cdot q^{2}+\left(2 \cdot P_{t}-P_{w}\right) \cdot(1-2 \cdot N) \cdot q+2 \cdot P_{t} \cdot N \cdot(N-1)}{2}
\end{aligned}
$$

Equation (A1) accumulates the points obtained by the first $q$ teams, which win in cascade, with the points obtained by the teams from $q+1$, which tie.

On the one hand, we have the following:

$$
\begin{aligned}
\sum_{i=1}^{N} p_{i}^{2}= & \sum_{i=1}^{q}\left(p_{w} \cdot(N-i)\right)^{2}+\sum_{i=q+1}^{N}\left(p_{t}(N-q-1)\right)^{2}=p_{w}^{2} \cdot\left[\sum_{I=1}^{q}\left(N^{2}-2 \cdot N \cdot i+i^{2}\right)\right] \\
& +p_{t}^{2}(N-q-1)^{2} \cdot \sum_{i=q+1}^{N} 1 \\
& =p_{w}^{2} \cdot\left[\sum_{i=1}^{q} N^{2}-2 \cdot N \cdot \sum_{i=1}^{q} i+\sum_{i=1}^{q} i^{2}\right]+p_{t}^{2}(N-q-1)^{2} \cdot(N-q)
\end{aligned}
$$

Given that

$\sum_{i=1}^{q} i=\frac{q \cdot(1+q)}{2}$ and $\sum_{i=1}^{q} i^{2}=\frac{q \cdot(q+1) \cdot(2 \cdot q+1)}{6}$, we have that

$$
\sum_{i=1}^{q} N^{2}-2 \cdot N \cdot \sum_{i=1}^{q} i+\sum_{i=1}^{q} i^{2}=N^{2} \cdot q-2 \cdot N \cdot \frac{q \cdot(1+q)}{2}+\frac{q \cdot(q+1) \cdot(2 \cdot q+1)}{6}
$$

Then,

$$
\sum_{i=1}^{N} p_{i}^{2}=p_{w}^{2}\left(N^{2} \cdot q-N \cdot q \cdot(1+q)+\frac{q \cdot(q+1) \cdot(2 \cdot q+1)}{6}\right)+p_{t}^{2} \cdot(N-q-1)^{2} \cdot(N-q)
$$

Therefore,

$$
\sum_{i=1}^{N} s_{i}^{2}=\frac{p_{w}^{2} \cdot\left(N^{2} \cdot q-N \cdot q \cdot(1+q)+\frac{q \cdot(q+1) \cdot(2 \cdot q+1)}{6}\right)+p_{t}^{2} \cdot(N-q-1)^{2} \cdot(N-q)}{\left(\frac{p_{w} \cdot q \cdot(2 \cdot N-q-1)}{2}+p_{t} \cdot(N-q-1) \cdot(N-q)\right)^{2}}
$$

We can reformulate it as a function of $(q)$. Thus, HHI is a function of a quotient of polynomials in $(q)$, which have as parameters the scoring system and number of teams:

$$
\begin{aligned}
\sum_{i=1}^{N} s_{i}^{2}=\frac{\sum_{1}^{N} p_{i}^{2}}{\left(\sum_{1}^{N} p_{i}\right)^{2}} & = \\
& =\frac{\left(\frac{p_{w}^{2}}{3}-p_{t}^{2}\right) \cdot q^{3}+\left(\left(3 \cdot p_{t}^{2}-p_{w}^{2}\right) \cdot N+\frac{1}{2} p_{w}^{2}-2 \cdot p_{t}^{2}\right) \cdot q^{2}}{\left(\frac{\left(2 \cdot p_{t}-p_{w}\right) \cdot q^{2}+\left(2 \cdot p_{t}-p_{w}\right) \cdot(1-2 \cdot N) \cdot q+2 \cdot p_{t} \cdot N \cdot(N-1)}{2}\right)^{2}} \\
& +\frac{\left(\left(p_{w}^{2}-3 \cdot p_{t}^{2}\right) \cdot N^{2}+\left(4 \cdot p_{t}^{2}-p_{w}^{2}\right) \cdot N+\frac{1}{6} \cdot p_{w}^{2}-p_{t}^{2}\right) \cdot q+p_{t}^{2} \cdot N \cdot(N-1)^{2}}{\left(\frac{\left(2 \cdot p_{t}-p_{w}\right) \cdot q^{2}+\left(2 \cdot p_{t}-p_{w}\right) \cdot(1-2 \cdot N) \cdot q+2 \cdot p_{t} \cdot N \cdot(N-1)}{2}\right)^{2}}
\end{aligned}
$$


For $\{3,1,0\}$, the former expression is reduced to the following:

$$
H H I(q)=\frac{2 \cdot q^{3}+\left(-6 \cdot N+\frac{5}{2}\right) \cdot q^{2}+\left(6 \cdot N^{2}-5 \cdot N+\frac{1}{2}\right) \cdot q+N \cdot(N-1)^{2}}{\left(\frac{-q^{2}-(1-2 \cdot N) \cdot q+2 \cdot N \cdot(N-1)}{2}\right)^{2}}
$$

\section{Appendix B}

Lemma A1. For every $N, H H I(q)$ has a maximum and minimum for $q \in[0, N-1]$.

Proof of Lemma A1. The HHI function is continuous and defined for $q \in[0, N-1]$. This completes the proof of the lemma.

Lemma A2. For $q_{1}>q_{2}$, then $\left[\sum_{1}^{N} p_{i}^{2}\right]_{q}<\left[\sum_{1}^{N} p_{i}^{2}\right]_{q+1}$, and $\left[\left(\sum_{1}^{N} p_{i}\right)^{2}\right]_{q}<\left[\left(\sum_{1}^{N} p_{i}\right)^{2}\right]_{q+1}$.

Proof of Lemma A2. If $q_{1}>q_{2}$ then, as for $q_{1}$ there are more wins in the tournament, the sum of points grows by incorporating 1 point for each win. Therefore, both $\sum_{1}^{N} p_{i}^{2}$ and $\left(\sum_{1}^{N} p_{i}\right)^{2}$ are higher for $q_{1}$ than for $q_{2}$. This completes the proof of the lemma.

Considering the results of Lemmas 1 and 2, Theorem 1 can be proved.

Proof of Theorem 1. For Lemma A1, HHI has a maximum for $q \in[0, N-1]$. We will prove it by reductio ad absurdum. For this, let us suppose that the maximum is not unique and $q_{1}<q_{2}$ both reach the maximum value, $\operatorname{HHI}\left(q_{1}\right)=\operatorname{HHI}\left(q_{2}\right)$. When we change from $q_{1}$ to $q_{2}$, a tie is replaced by a win; therefore, by adding 1 additional point per win, the total championship points for the Truncated cascade distribution for $q_{1}$ is less than for $q_{2}$.

Using Lemma 2, we know that dividends and the divisor of HHI grow. However, by construction, the numerator grows slower than the denominator, so the same value of HHI cannot be reached for $q_{1}$ as for $q_{2}$. Therefore, the HHI for $q \in[0, N-1]$ has a unique maximum. The same reasoning can be applied to the minimum.

However, we have already indicated that the perfectly balanced distribution is one in which all teams score the same points and the value of the index for this distribution is $1 / N$. Therefore, the range of variation of the $\mathrm{HHI}$ is $[1 / N, 1]$.

\section{Appendix C}

Proof of Theorem 2. From Proposition 1,

$$
\left[\sum_{i=1}^{N} p_{i}\right]_{q}=\frac{\left(2 \cdot p_{t}-p_{w}\right) \cdot q^{2}+\left(2 \cdot p_{t}-p_{w}\right) \cdot(1-2 \cdot N) \cdot q+2 \cdot p_{t} \cdot N \cdot(N-1)}{2}
$$

$$
\begin{aligned}
\left(\left[\sum_{i=1}^{N} p_{i}\right]_{q}\right)^{2}= & \left(\frac{\left(2 \cdot p_{t}-p_{w}\right) \cdot q^{2}+\left(2 \cdot p_{t}-p_{w}\right) \cdot(1-2 \cdot N) \cdot q+2 \cdot p_{t} \cdot N \cdot(N-1)}{2}\right)^{2} \\
& =\frac{1}{4}\left\{\left(2 \cdot p_{t}-p_{w}\right)^{2} \cdot q^{4}+2 \cdot\left(2 \cdot p_{t}-p_{w}\right)^{2} \cdot(1-2 \cdot N) \cdot q^{3}\right. \\
& +\left[\left(2 \cdot p_{t}-p_{t}\right)^{2} \cdot(1-2 \cdot N)^{2}+4 \cdot\left(2 \cdot p_{t}-p_{w}\right) \cdot p_{t} \cdot N \cdot(N-1)\right] \cdot q^{2}+2 \cdot\left(2 \cdot p_{t}-p_{w}\right) \\
& \left.\cdot(1-2 \cdot N) \cdot 2 \cdot p_{t} \cdot N \cdot(N-1) \cdot q+4 \cdot p_{t}{ }^{2} \cdot N^{2} \cdot(N-1)^{2}\right\}
\end{aligned}
$$




$$
\begin{aligned}
{\left[\sum_{i=1}^{N} p_{i}^{2}\right]_{q}=} & \left(\frac{p_{w}^{2}}{3}-p_{t}^{2}\right) \cdot q^{3}+\left(\left(3 \cdot p_{t}^{2}-p_{w}^{2}\right) \cdot N+\frac{1}{2} p_{w}^{2}-2 \cdot p_{t}^{2}\right) \cdot q^{2} \\
& +\left(\left(p_{w}^{2}-3 \cdot p_{t}^{2}\right) \cdot N^{2}+\left(4 \cdot p_{t}^{2}-p_{w}^{2}\right) \cdot N+\frac{1}{6} \cdot p_{w}^{2}-p_{t}^{2}\right) \cdot q+p_{t}^{2} \cdot N \cdot(N-1)^{2}
\end{aligned}
$$

First step: We calculate the expressions for $0 \leq q \leq N-1$ with $q \in \mathbb{N}$ of $\left[\sum_{i=1}^{N} p_{i}\right]_{q+1^{\prime}}$ $\left(\left[\sum_{i=1}^{N} p_{i}\right]_{q+1}\right)^{2}$, and $\left[\sum_{i=1}^{N} p_{i}^{2}\right]_{q+1}$.

$$
\left[\sum_{i=1}^{N} p_{i}\right]_{q+1}=\left[\sum_{i=1}^{N} p_{i}\right]_{q}+\left(P_{w}-2 \cdot P_{t}\right) \cdot(N-q-1)
$$

$\left(\left[\sum_{i=1}^{N} p_{i}\right]_{q+1}\right)^{2}$

$$
\begin{aligned}
& =\left(\left[\sum_{i=1}^{N} p_{i}\right]_{q}\right)^{2}+2 \cdot\left(P_{w}-2 \cdot P_{t}\right) \cdot(N-q-1) \cdot\left[\sum_{i=1}^{N} p_{i}\right]_{q}+\left(P_{w}-2 \cdot P_{t}\right)^{2} \\
& \cdot(N-q-1)^{2}
\end{aligned}
$$

$$
\begin{aligned}
{\left[\sum_{i=1}^{N} p_{i}^{2}\right]_{q+1}=} & {\left[\sum_{i=1}^{N} p_{i}^{2}\right]_{q}+\left[3 \cdot\left(\frac{P_{w}^{2}}{3}-P_{t}^{2}\right)\right] \cdot q^{2} } \\
& +\left[3 \cdot\left(\frac{P_{w}^{2}}{3}-P_{t}^{2}\right)+2 \cdot\left(P_{w}^{2} \cdot\left(-N+\frac{1}{2}\right)+P_{t}^{2} \cdot(3 \cdot N-2)\right)\right] \cdot q+\left(\frac{P_{w}^{2}}{3}-P_{t}^{2}\right) \\
& +\left(P_{w}^{2} \cdot\left(-N+\frac{1}{2}\right)+P_{t}^{2} \cdot(3 \cdot N-2)\right) \\
& +\left(P_{w}^{2} \cdot\left(N^{2}-N+\frac{1}{6}\right)+P_{t}^{2} \cdot\left(-3 \cdot N^{2}+4 \cdot N-1\right)\right)
\end{aligned}
$$

Second step: For the scoring system $\{3,1,0\},\left(2 \cdot P_{t}-P_{w}\right)=-1$, substituting, we obtain the following:

$$
\left[\sum_{i=1}^{N} p_{i}\right]_{q+1}-\left[\sum_{i=1}^{N} p_{i}\right]_{q}=(N-q-1)
$$

$$
\left(\left[\sum_{i=1}^{N} p_{i}\right]_{q+1}\right)^{2}-\left(\left[\sum_{i=1}^{N} p_{i}\right]_{q}\right)^{2}=q^{3}-3 \cdot(N-1) \cdot q^{2}-3 \cdot(N-1) \cdot q+(N-1)^{2} \cdot(2 \cdot N+1)
$$

On the other hand, as

$$
\left(\frac{P_{g}^{2}}{3}-P_{e}^{2}\right)=\left(\frac{9}{3}-1\right)=2
$$

and

$$
\left(P_{w}^{2} \cdot\left(-N+\frac{1}{2}\right)+P_{t}^{2} \cdot(3 \cdot N-2)\right)=\frac{9}{2}-9 \cdot N+3 \cdot N-2=-6 \cdot N+\frac{5}{2}
$$

and

$$
\begin{aligned}
& \left(P_{w}^{2} \cdot\left(N^{2}-N+\frac{1}{6}\right)+P_{t}^{2} \cdot\left(-3 \cdot N^{2}+4 \cdot N-1\right)\right) \\
& =9 \cdot N^{2}-9 \cdot N+\frac{3}{2}-3 \cdot N^{2}+4 \cdot N-1 \\
& =6 \cdot N^{2}-5 \cdot N+\frac{1}{2}
\end{aligned}
$$

Therefore,

$$
\left[\sum_{i=1}^{N} p_{i}^{2}\right]_{q+1}-\left[\sum_{i=1}^{N} p_{i}^{2}\right]_{q}=6 \cdot q^{2}+(11-12 \cdot N) \cdot q+6 \cdot N^{2}-11 \cdot N+5
$$


where,

$$
\begin{gathered}
{\left[\sum_{i=1}^{N} p_{i}\right]_{q}=\frac{-q^{2}-(1-2 \cdot N) \cdot q+2 \cdot N \cdot(N-1)}{2}} \\
\left(\left[\sum_{i=1}^{N} p_{i}\right]_{q}\right)^{2}=\frac{1}{4}\left\{q^{4}+2 \cdot(1-2 \cdot N) \cdot q^{3}+q^{2}-4 \cdot(1-2 \cdot N) \cdot N \cdot(N-1) \cdot q+4 \cdot N^{2} \cdot(N-1)^{2}\right\} \\
{\left[\sum_{i=1}^{N} p_{i}^{2}\right]_{q}=2 \cdot q^{3}+\left(-6 \cdot N+\frac{5}{2}\right) \cdot q^{2}+\left(6 \cdot N^{2}-5 \cdot N+\frac{1}{2}\right) \cdot q+N \cdot(N-1)^{2}}
\end{gathered}
$$

Third step: The unique maximum of HHI must verify that $\left[\sum_{i=1}^{N} s_{i}^{2}\right]_{q+1}<\left[\sum_{i=1}^{N} s_{i}^{2}\right]_{q}$.

$$
\left[\sum_{i=1}^{N} s_{i}^{2}\right]_{q+1}<\left[\sum_{i=1}^{N} s_{i}^{2}\right]_{q} \stackrel{\text { eq.to }}{\Leftrightarrow} \frac{\frac{\left[\sum_{I=1}^{N} p_{i}^{2}\right]_{q+1}}{\left[\sum_{I=1}^{N} p_{i}^{2}\right]_{q}}}{\frac{\left[\left(\sum_{i=1}^{N} p_{i}\right)^{2}\right]_{q+1}}{\left[\left(\sum_{i=1}^{N} p_{i}\right)^{2}\right]_{q}}}<1
$$

By applying the results of Equation (A18) to Equation (A19), we get the following:

$$
\begin{aligned}
1>\frac{\left[\sum_{I=1}^{N} p_{i}^{2}\right]_{q+1}}{\frac{\left[\sum_{I=1}^{N} p_{i}\right]_{q}}{\left[\left(\sum_{i=1}^{N} p_{i}\right)^{2}\right]_{q+1}}} & \\
& =\frac{\frac{\left[\sum_{I=1}^{N} p_{i}^{2}\right]_{q}+6 \cdot q^{2}+(11-12 \cdot N) \cdot q+6 \cdot N^{2}-11 \cdot N+5}{\left.\left[\Sigma_{i=1}^{N} p_{i}\right)^{2}\right]_{q}}}{\frac{\left[\sum_{I=1}^{N} p_{i}^{2}\right]_{q}}{\left[\left(\Sigma_{i=1}^{N} p_{i}\right)^{2}\right]_{q}+q^{3}-3 \cdot(N-1) \cdot q^{2}-3 \cdot(N-1) \cdot q+(N-1)^{2} \cdot(2 \cdot N+1)}} \\
& ==\frac{1+\frac{6 \cdot q^{2}+(11-12 \cdot N) \cdot q+6 \cdot N^{2}-11 \cdot N+5}{\left[\sum_{I=1}^{N} p_{i}^{2}\right]_{q}}}{1+\frac{q^{3}-3 \cdot(N-1) \cdot q^{2}-3 \cdot(N-1) \cdot q+(N-1)^{2} \cdot(2 \cdot N+1)}{\left[\left(\sum_{i=1}^{N} p_{i}\right)^{2}\right]_{q}}}
\end{aligned}
$$

which is equivalent to the following:

$$
\begin{gathered}
\frac{q^{3}-3 \cdot(N-1) \cdot q^{2}-3 \cdot(N-1) \cdot q+(N-1)^{2} \cdot(2 \cdot N+1)}{\left[\left(\sum_{i=1}^{N} p_{i}\right)^{2}\right]_{q}} \\
>\frac{6 \cdot q^{2}+(11-12 \cdot N) \cdot q+6 \cdot N^{2}-11 \cdot N+5}{\left[\sum_{I=1}^{N} p_{i}^{2}\right]_{q}}
\end{gathered}
$$

Fourth step: The cut-off value of $q$ to obtain the least balanced distribution must meet the following:

$$
\frac{(q-(N-1)) \cdot\left[q^{2}-2 \cdot(N-1) \cdot q-(N-1) \cdot(2 \cdot N+1)\right]}{\frac{1}{4}\left\{q^{4}+2 \cdot(1-2 \cdot N) \cdot q^{3}+q^{2}-4 \cdot(1-2 \cdot N) \cdot N \cdot(N-1) \cdot q+4 \cdot N^{2} \cdot(N-1)^{2}\right\}}
$$

Simplifying the following:

$$
\begin{aligned}
(q-(N-1)) \cdot & {\left[2 \cdot q^{5}+\left(-10 \cdot N+\frac{13}{2}\right) q^{4}+\left(14 \cdot N^{2}-20 \cdot N+\frac{15}{2}\right) q^{3}\right.} \\
& +\left(N^{3}+9 \cdot N^{2}-\frac{27}{2} \cdot N+\frac{7}{2}\right) q^{2}+\left(-14 \cdot N^{4}+22 \cdot N^{3}-6 \cdot N^{2}-\frac{5}{2} \cdot N+\frac{1}{2}\right) \cdot q-N \\
& \left.\cdot\left(2 \cdot N^{4}-5 \cdot N^{3}+3 \cdot N^{2}+N-1\right)\right] \\
& >\frac{(q-(N-1))}{4}\left[6 \cdot q^{5}+(-30 \cdot N+17) q^{4}+\left(24 \cdot N^{2}-32 \cdot N+16\right) q^{3}\right. \\
& +\left(48 \cdot N^{3}-72 \cdot N^{2}+18 \cdot N+5\right) q^{2}+4 \cdot\left(-6 \cdot N^{4}+16 \cdot N^{3}-15 \cdot N^{2}+5 \cdot N\right) \cdot q \\
& \left.+N^{2} \cdot\left(-6 \cdot N^{3}+17 \cdot N^{2}-16 \cdot N+5\right)\right]
\end{aligned}
$$


By operating inequality, the resulting inequation is as follows:

$$
\begin{aligned}
0> & {\left[-\frac{1}{2} \cdot q^{5}+\left(\frac{5}{2} \cdot N-\frac{9}{4}\right) \cdot q^{4}+\left(-8 \cdot N^{2}+12 \cdot N-\frac{7}{2}\right) \cdot q^{3}+\left(11 \cdot N^{3}-27 \cdot N^{2}+18 \cdot N-\frac{9}{4}\right) \cdot q^{2}\right.} \\
& \left.+\left(8 \cdot N^{4}-6 \cdot N^{3}-9 \cdot N^{2}+\frac{15}{2} \cdot N-\frac{1}{2}\right) \cdot q-4 \cdot N^{5}+12 \cdot N^{4}-13 \cdot N^{3}+6 \cdot N^{2}-N\right]
\end{aligned}
$$

\section{References}

1. Hirschman, A.O. National Power and the Structure of Foreign Trade; University of California Press: Berkeley, CA, USA, 1945.

2. Erreygers, G. Correcting the Concentration Index. J. Health Econ. 2009, 28, 504-515. [CrossRef]

3. Koolman, X.; van Doorslaer, E. On the Interpretation of a Concentration Index of Inequality. Health Econ. 2004, 13, 649-656. [CrossRef]

4. Feld, S.L.; Grofman, B. The Laakso-Taagepera Index in A Mean and Variance Framework, The Laakso-Taagepera Index in A Mean and Variance Framework. J. Theor. Polit. 2007, 19, 101-106. [CrossRef]

5. Laakso, M.; Taagepera, R. "Effective" Number of Parties: A Measure with Application to West Europe. Comp. Polit. Stud. 1979, 12, 3-27. [CrossRef]

6. Andreff, W. Disequilibrium Sports Economics: Competitive Imbalance and Budget Constraints; Edward Elgar Publishing: Cheltenham, UK, 2015; ISBN 978-1-78347-936-8.

7. Depken, C.A. Free-Agency and the Competitiveness of Major League Baseball. Rev. Ind. Organ. 1999, 14, 205-217. [CrossRef]

8. Alonso-Villar, O.; Río, C.D. Concentration of Economic Activity: Inequality-Based Measures. Spat. Econ. Anal. 2012, 7, 223-246. [CrossRef]

9. Greenberg, J.H. The Measurement of Linguistic Diversity. Language 1956, 32, 109-115. [CrossRef]

10. Lieberson, S. An Extension of Greenberg's Linguistic Diversity Measures. Language 1964, 40, 526-531. [CrossRef]

11. Tóth, J. Bounds of Herfindahl-Hirschman Index of Banks in the European Union. Available online: https://mpra.ub.unimuenchen.de/72922/ (accessed on 28 October 2018).

12. Khurshid, S.M.Z.; Rohit; Singh, G.P. Levels and Trends of Competition Among the Mutual Funds in India. Res. J. Bus. Manag. 2009, 3, 47-67. [CrossRef]

13. Davydov, D.; Weber, S. A Simple Characterization of the Family of Diversity Indices. Econ. Lett. 2016, 147, 121-123. [CrossRef]

14. Owen, P.D.; Owen, C.A. Simulation Evidence on Herfindahl-Hirschman Measures of Competitive Balance in Professional Sports Leagues. J. Oper. Res. Soc. 2020, 1-16. [CrossRef]

15. Neale, W.C. The Peculiar Economics of Professional Sports*. Q. J. Econ. 1964, 78, 1-14. [CrossRef]

16. UEFA UEFA President: Aleksander Čeferin I Inside UEFA. Available online: https://www.uefa.com/insideuefa/about-uefa/ president/ (accessed on 6 August 2020).

17. Rottenberg, S. The Baseball Players' Labor Market. J. Polit. Econ. 1956, 64, 242-258. [CrossRef]

18. Berri, D.; Schmidt, M.; Brook, S. The Wages of Wins: Taking Measure of the Many Myths in Modern Sport. Updated Edition; Stanford Business Books: Stanford, CA, USA, 2007; ISBN 978-0-8047-5844-4.

19. Coates, D.; Humphreys, B.R.; Zhou, L. Reference-Dependent Preferences, Loss Aversion, and Live Game Attendance. Econ. Inq. 2014, 52, 959-973. [CrossRef]

20. Wright, M.B. 50 Years of OR in Sport. J. Oper. Res. Soc. 2009, 60, S161-S168. [CrossRef]

21. Owen, P.D.; Owen, C.A. Simulation Evidence on Herfindahl-Hirschman Indices as Measures of Competitive Balance. Econ. Discuss. Pap. 2017, 1750.

22. Könemann, J.; Pashkovich, K.; Toth, J. Computing the Nucleolus of Weighted Cooperative Matching Games in Polynomial Time. Math. Program. 2020, 183, 555-581. [CrossRef]

23. Friesl, M.; Lenten, L.J.A.; Libich, J.; Stehlík, P. In Search of Goals: Increasing Ice Hockey's Attractiveness by a Sides Swap. J. Oper. Res. Soc. 2017, 68, 1006-1018. [CrossRef]

24. Goossens, D.R.; Beliën, J.; Spieksma, F.C.R. Comparing League Formats with Respect to Match Importance in Belgian Football. Ann. Oper. Res. 2012, 194, 223-240. [CrossRef]

25. Kendall, G.; Lenten, L.J.A. When Sports Rules Go Awry. Eur. J. Oper. Res. 2017, 257, 377-394. [CrossRef]

26. Scarf, P.; Yusof, M.M.; Bilbao, M. A Numerical Study of Designs for Sporting Contests. Eur. J. Oper. Res. 2009, 198, 190-198. [CrossRef]

27. Szymanski, S. The Economic Design of Sporting Contests. J. Econ. Lit. 2003, 41, 1137-1187. [CrossRef]

28. Fort, R.; Maxcy, J. “Competitive Balance in Sports Leagues: An Introduction”. J. Sports Econ. 2003, 4, 154-160. [CrossRef]

29. McGee, M.K. Two Universal, Probabilistic Measures of Ompetitive Imbalance. Appl. Econ. 2016, 48, 2883-2894. [CrossRef]

30. Bowman, R.A.; Ashman, T.; Lambrinos, J. Prospective Measures of Competitive Balance: Application to Money Lines in Major League Baseball. Appl. Econ. 2013, 45, 4071-4081. [CrossRef]

31. Bowman, R.A.; Lambrinos, J.; Ashman, T. Competitive Balance in the Eyes of the Sports Fan: Prospective Measures Using Point Spreads in the NFL and NBA. J. Sports Econ. 2013, 14, 498-520. [CrossRef] 
32. Bowman, R.A.; Lambrinos, J.; Ashman, T. Prospective Measures of Competitive Balance Application to Money Lines in the National Hockey League. Appl. Econ. 2018, 50, 1-12. [CrossRef]

33. Larsen, A.; Fenn, A.J.; Spenner, E.L. The Impact of Free Agency and the Salary Cap on Competitive Balance in the National Football League. J. Sports Econ. 2006, 7, 374-390. [CrossRef]

34. Kringstad, M.; Gerrard, B. The concepts of competitive balance and uncertainty of outcome. In The Economics and Management of Mega Athletic Events: Olympic Games, Professional Sports and Other Essays; Papanikos, G.T., Ed.; Athens Institute For Education and Research: Athens, Greece, 2004; pp. 115-130.

35. Zimbalist, A.S. Competitive Balance in Sports Leagues: An Introduction. J. Sports Econ. 2002, 3, 111-121. [CrossRef]

36. Schmidt, M.B. Competition in Major League Baseball: The Impact Expansion. Appl. Econ. Lett. 2001, 8, 21-26. [CrossRef]

37. Schmidt, M.B.; Berri, D.J. Competitive Balance and Attendance: The Case of Major League Baseball. J. Sports Econ. 2001, 2, 145-167. [CrossRef]

38. Utt, J.; Fort, R. Pitfalls to Measuring Competitive Balance With Gini Coefficients. J. Sports Econ. 2002, 3, 367-373. [CrossRef]

39. Gayant, J.P.; Le Pape, N. The metrics of competitive imbalance. In Disequilibrium Sports Economy: Competitive Imbalance and Budget Constraints; Andreff, W., Ed.; Edward Elgar Publishing: Cheltenham, UK, 2015; pp. 104-130.

40. Michie, J.; Oughton, C. Competitive Balance in Football: Trends and Effects; Football Governance Research Centre, Birkbeck College, University of London: London, UK, 2004.

41. Horowitz, I. The Increasing Competitive Balance in Major League Baseball. Rev. Ind. Organ. 1997, 12, 373-387. [CrossRef]

42. Humphreys, B. Alternative Measures of Competitive Balance in Sports Leagues. J. Sports Econ. 2002, 3, 133-148. [CrossRef]

43. Borooah, V.K.; Mangan, J. Measuring Competitive Balance in Sports Using Generalized Entropy with an Application to English Premier League Football. Appl. Econ. 2012, 44, 1093-1102. [CrossRef]

44. Lenten, L.J.A. Unbalanced Schedules and the Estimation of Competitive Balance in the Scottish Premier League. Scott. J. Polit. Econ. 2008, 55, 488-508. [CrossRef]

45. Pawlowski, T.; Breuer, C.; Hovemann, A. Top Clubs' Performance and the Competitive Situation in European Domestic Football Competitions. J. Sports Econ. 2010, 11, 186-202. [CrossRef]

46. Kharrat, T.; McHale, I.G.; Peña, J.L. Plus-Minus Player Ratings for Soccer. Eur. J. Oper. Res. 2020, 283, 726-736. [CrossRef]

47. Davies, S. Choosing between Concentration Indices: The Iso-Concentration Curve. Economica 1979, 46, 67-75. [CrossRef]

48. Geroski, P.A. Some Reflections on the Theory and Application of Concentration Indices. Int. J. Ind. Organ. 1983, 1, 79-94. [CrossRef]

49. Hall, M.; Tideman, N. Measures of Concentration. J. Am. Stat. Assoc. 1967, 62, 162-168. [CrossRef]

50. Eckard, E.W. The Uncertainty-of-Outcome Hypothesis and the Industrial Organization of Sports Leagues: Evidence From U.S College Football. J. Sports Econ. 2017, 18, 298-317. [CrossRef]

51. Lenten, L.J.A. Measurement of Competitive Balance in Conference and Divisional Tournament Design. J. Sports Econ. 2015, 16, 3-25. [CrossRef]

52. Brandes, L.; Franck, E. Who Made Who? An Empirical Analysis of Competitive Balance in European Soccer Leagues. East. Econ. J. 2007, 33, 379-403. [CrossRef]

53. Gasparetto, T.; Barajas, A. Playoffs or Just League: A Debate in Brazilian Football. Open Sports Sci. J. 2016, 9. [CrossRef]

54. Martinez, M.; Willner, J. Competitive Balance and Consumer Demand in the English Football League. Appl. Financ. Account. 2017, 3, 49-60. [CrossRef]

55. Triguero-Ruiz, F.; Avila-Cano, A. Measuring Competitive Balance in the Major European Soccer Leagues. J. Phys. Educ. Sport 2018, 18, 1335-1340. [CrossRef]

56. Lenten, L.J.A. A Formal Test for Asymmetry in the Uncertainty of Outcome Hypothesis. J. Sports Econ. 2017, 18, 253-270. [CrossRef]

57. Lenten, L.J.A. Towards a New Dynamic Measure of Competitive Balance: A Study Applied to Australia's Two Major Professional 'Football' Leagues. Econ. Anal. Policy 2009, 39, 407-428. [CrossRef]

58. Owen, P.D.; Ryan, M.; Weatherston, C.R. Measuring Competitive Balance in Professional Team Sports Using the HerfindahlHirschman Index. Rev. Ind. Organ. 2007, 31, 289-302. [CrossRef]

59. Jane, W.-J. The Relationship Between Outcome Uncertainties and Match Attendance: New Evidence in the National Basketball Association. Rev. Ind. Organ. 2014, 45, 177-200. [CrossRef]

60. Jane, W.-J. The Effect of Star Quality on Attendance Demand: The Case of the National Basketball Association. J. Sports Econ. 2016, 17, 396-417. [CrossRef]

61. del Corral, J.; García-Unanue, J.; Herencia-Quintanar, F. Are NBA Policies That Promote Long-Term Competitive Balance Effective? What Is the Price? Open Sports Sci. J. 2016, 9. [CrossRef]

62. Fenn, A.J.; von Allmen, P.; Brook, S.; Preissing, T.J. The Influence of Structural Changes and International Players on Competitive Balance in the NHL. Atl. Econ. J. 2005, 33, 215-224. [CrossRef]

63. Howarth, A.; Robinson, T.A. The Impact of the Salary Cap in the European Rugby Super League. Int. J. Bus. Manag. 2008,3 , 3-7. [CrossRef]

64. Tainsky, S.; Xu, J.; Yang, Q. Competitive Balance and the Participation-Spectatorship Gap in Chinese Table Tennis. Appl. Econ. 2017, 49, 263-272. [CrossRef]

65. Totty, E.S.; Owens, M.F. Salary Caps And Competitive Balance In Professional Sports Leagues. J. Econ. Educ. 2011, 11, 45-56. 
66. Triguero-Ruiz, F.; Avila-Cano, A. The Distance to Competitive Balance: A Cardinal Measure. Appl. Econ. 2019, 51, 698-710. [CrossRef]

67. Avila-Cano, A.; Triguero-Ruiz, F. The Distribution of Soccer Leagues Scores That Generates the Minimum of Competitive Balance: Truncated-Cascade Distribution; Universidad de Malaga, Department of Economic Theory, Malaga Economic Theory Research Center: Málaga, Spain, 2018.

68. Vaziri, B.; Dabadghao, S.; Yih, Y.; Morin, T.L. Properties of Sports Ranking Methods. J. Oper. Res. Soc. 2018, 69, 776-787. [CrossRef]

69. Fort, R.; Quirk, J. Cross-Subsidization, Incentives, and Outcomes in Professional Team Sports Leagues. J. Econ. Lit. 1995, 33, 1265-1299.

70. Gayant, J.P.; Le Pape, N. How to Account for Changes in the Size of Sports Leagues? The Iso Competitive Balance Curves. Econ. Bull. 2012, 32, 1715-1723.

71. Zambom-Ferraresi, F.; García-Cebrián, L.I.; Lera-López, F.; Iráizoz, B. Performance Evaluation in the UEFA Champions League. J. Sports Econ. 2017, 18, 448-470. [CrossRef]

72. Bradbury, J.C. Determinants of Revenue in Sports Leagues: An Empirical Assessment. Econ. Inq. 2019, 57, 121-140. [CrossRef] 